\title{
Non-Vitamin K Oral Anticoagulants for Stroke Prevention in Special Populations with Atrial Fibrillation
}

\author{
Arnaud Bisson · Denis Angoulvant · Raphael Philippart · Nicolas Clementy • \\ Dominique Babuty · Laurent Fauchier
}

Received: February 27, 2017 / Published online: May 10, 2017

(C) The Author(s) 2017. This article is an open access publication

\begin{abstract}
Atrial fibrillation (AF) is associated with an increased risk of ischemic stroke or systemic embolism compared with normal sinus rhythm. These strokes may efficiently be prevented in patients with risk factors using oral anticoagulant therapy, with either vitamin $\mathrm{K}$ antagonists (VKAs) or non-vitamin $\mathrm{K}$ antagonist oral anticoagulants (NOACs) (i.e., direct thrombin inhibitors or direct factor Xa inhibitors). Owing to their specific risk profiles, some AF populations may have increased risks of both thromboembolic and bleeding events. These $\mathrm{AF}$ patients may be denied oral anticoagulants, whilst evidence shows that the absolute benefits of oral anticoagulants are greatest in patients at highest risk. NOACs are an alternative to VKAs to prevent stroke in patients with "non-valvular $\mathrm{AF}^{\prime \prime}$, and NOACs may offer a greater net clinical benefit compared with VKAs, particularly in these high-risk patients. Physicians have to learn how to use these drugs optimally in specific settings. We review concrete clinical
\end{abstract}

Enhanced content To view enhanced content for this article go to http://www.medengine.com/Redeem/ 8E18F06042BA66C1.

A. Bisson - D. Angoulvant · R. Philippart .

N. Clementy · D. Babuty · L. Fauchier $(\bowtie)$

Service de Cardiologie, Centre Hospitalier

Universitaire Trousseau et Faculté de Médecine,

Université François Rabelais, Tours, France

e-mail: lfau@med.univ-tours.fr scenarios for which practical answers are currently proposed for use of NOACs based on available evidence for patients with kidney disease, elderly patients, women, patients with diabetes, patients with low or high body weight, and those with valve disease.

Keywords: Apixaban; Atrial fibrillation; Dabigatran; Oral anticoagulants; Rivaroxaban

\section{INTRODUCTION}

The management of atrial fibrillation (AF) has recently changed with the availability of non-vitamin $\mathrm{K}$ oral anticoagulants (NOACs), which have provided an alternative to vitamin $\mathrm{K}$ antagonists (VKAs) in preventing thromboembolic events [1]. It would be expected that their prescription rate will increase during the years to come if the possible additional cost is accepted by health systems. However, some characteristics or comorbidities commonly seen in patients with AF may complicate their management or cause the prescriber to question the best treatment option. This may particularly be the case for patients with kidney disease, older age, extremely high or low weight, or valvular disease. We present a brief review of recommendations based on the available published data in these special populations. 


\section{Compliance with Ethics Guidelines}

This article is based on previously conducted studies and does not involve any new studies of human or animal subjects performed by any of the authors.

\section{PATIENTS WITH CHRONIC KIDNEY DISEASE}

Impairment of renal function increases the risk of thromboembolic and hemorrhagic complications in patients with AF [2-5]. The risk-benefit ratio of NOACs in patients with chronic kidney disease may be better appreciated considering that:

- NOACs are all partly eliminated by the kidneys, causing a pharmacokinetic interaction in the case of chronic kidney disease.

- It is recommended to estimate renal function for AF patients using the Cockcroft-Gault formula used in clinical trials evaluating NOACs.

- Current knowledge indicates that NOACs should not be used in patients with dialysis or creatinine clearance less than $30 \mathrm{~mL} / \mathrm{min}$. Patients with moderate to severe chronic kidney disease (creatinine clearance 30-89 mL/ min) have not been included in clinical trials evaluating NOACs. However, post hoc analysis of these studies suggests that the superiority of NOACs over VKAs in reducing the risk of hemorrhagic complications is maintained even in patients with an estimated glomerular filtration rate of $30-50 \mathrm{~mL} / \mathrm{min}$ [6-9]. The European Society of Cardiology (ESC) and the European Heart Rhythm Association (EHRA) recommend the use of low doses of NOACs in these patients
(Table 1) [1, 7]. Some patients with a creatinine clearance of $25-29 \mathrm{~mL} / \mathrm{min}$ were included in the ARISTOTLE study [10], and the license for apixaban includes patients with a creatinine clearance of $15-30 \mathrm{~mL} / \mathrm{min}$. Low-dose anti-Xa NOACs are approved by the European Medicines Agency (EMA) for patients with an estimated clearance of $15-30 \mathrm{~mL} / \mathrm{min}$, but the ESC does not recommend them in these patients [1]. Dabigatran $75 \mathrm{mg}$ twice daily (BID) is approved in the USA, but not in Europe, for patients with an estimated clearance of $15-30 \mathrm{~mL} / \mathrm{min}$.

Once NOACs have been started, renal function monitoring is recommended at least annually to adjust doses. The following monitoring algorithm can be used: creatinine clearance $/ 10=$ number of months interval between two estimates of renal function (e.g., if clearance is $40 \mathrm{~mL} / \mathrm{min}$, renal function should be monitored every 4 months).

Hereafter are listed the main points to be remembered for daily practice concerning the use of NOACs in patients with chronic kidney disease and AF [7]:

- The superiority of NOACs over VKAs demonstrated in clinical trials is also observed in this population at higher risk of thromboembolic and hemorrhagic complications.

- The use of lower doses is recommended for patients with creatinine clearance $30-50 \mathrm{~mL} /$ min, also taking into account the patient's age and weight for apixaban.

- The use of anti-Xa NOACs could be considered with great caution in patients with creatinine clearance $15-30 \mathrm{~mL} / \mathrm{min}$.

- In the absence of evidence, all NOACs are contraindicated in patients requiring dialysis or with creatinine clearance less than $15 \mathrm{~mL} /$ $\min$.

Table 1 Use of NOACs in patients with AF and chronic kidney disease

\begin{tabular}{lllll}
\hline Creatinine clearance $(\mathbf{m L} / \mathbf{m i n})$ & Dabigatran & Apixaban & Edoxaban & Rivaroxaban \\
\hline$\geq 50$ & No adjustment & No adjustment & No adjustment & No adjustment \\
$\geq 30$ and $<50$ & $110 \mathrm{mg} \mathrm{BID}$ & $2.5 \mathrm{mg} \mathrm{BID}$ & $30 \mathrm{mg} \mathrm{OD}$ & $15 \mathrm{mg}$ OD \\
$<30$ & Not recommended & Not recommended & Not recommended & Not recommended \\
\hline
\end{tabular}

$B I D$ twice daily, $O D$ once daily

${ }^{a}$ If age $\geq 80$ years or weight $\leq 60 \mathrm{~kg}$ 
- Initial and subsequent monitoring of renal function using the Cockroft-Gault formula is recommended.

\section{ELDERLY PATIENTS}

All patients with AF aged over 75 years are eligible for anticoagulant therapy, as their thromboembolic risk is sufficiently high solely on the basis of their age $\left(\mathrm{CHA}_{2} \mathrm{DS}_{2}-\mathrm{VASc} \geq 2\right)$. However, anticoagulant therapy is underused in the elderly [11]. An assessment of bleeding risk, using the HAS-BLED or HEMORR2HAGES scores, is possible before prescribing anticoagulant therapy. The latter may be more suitable in elderly patients because it takes their risk of falls into account [12], but it is infrequently used in daily practice because it is more difficult to memorize. However, preliminary results indicate that the performance of HEMORR2HAGES and HAS-BLED is similar in the elderly [13]. HAS-BLED also draws attention to modifiable risk factors such as uncontrolled hypertension, medication predisposing to bleeding, or labile international normalized ratio (INR). Antiplatelet agents, without anticoagulants, have no advantage in the elderly, the benefit-risk profile being less favorable than for anticoagulants $[14,15]$.

The prescription of VKAs is associated with a high risk of adverse drug events, given the narrow therapeutic margin and the numerous drug and food interactions. VKAs are the leading cause of emergency hospitalizations for adverse events in the elderly [16]. Owing to their short half-life and predictable pharmacokinetics, which do not require biological monitoring other than renal function, NOACs are possible treatments in the elderly. Trials of NOACs in patients with AF have shown that they reduce the risk of intracranial hemorrhage, while being at least as efficient as VKAs. No studies have specifically analyzed the efficacy of NOACs in elderly patients, but a meta-analysis by Ruff et al. analyzed their efficacy and safety in more than 29,000 patients over 75 years of age [17]. A significant $22 \%$ decrease in thromboembolic risk was observed with NOACs compared with VKAs [relative risk, 0.78; 95\% confidence interval (CI) 0.68-0.88], without any change in the risk of major or non-major clinically significant bleeding (relative risk, 0.93; 95\% CI 0.74-1.17). The lack of statistical interaction with age in this analysis indicates that the conclusions to be drawn from the benefits of NOACs are similar for elderly subjects.

Chronic kidney disease, which is prevalent in the AF population, remains an important limitation for the prescription of NOACs in the elderly. A glomerular filtration rate greater than $30 \mathrm{~mL} / \mathrm{min}$, estimated by the Cockcroft-Gault formula, is a purely mathematical filter at the time of prescription of NOACs in most nonagenarians for current dosages. However, an expert consensus document has indicated a preference for anti-Xa NOACs instead of VKAs for elderly patients with a glomerular filtration rate $15-30 \mathrm{~mL} / \mathrm{min}$ [18]. This is in line with the marketing authorizations of rivaroxaban and apixaban, but in contradiction with most current recommendations of other scientific societies, e.g., the ESC suggests avoiding NOACs in patients with creatinine clearance $15-30 \mathrm{~mL} /$ $\min [1]$.

The notion of frailty in geriatric patients (involuntary weight loss, slow walking, low endurance, weakness/fatigue, reduced physical activity) [19] seems relevant to identify an excessive risk of using anticoagulation in some elderly subjects and in the very elderly. Pre-fragile states (one or two criteria among those listed above) and fragile (three or more criteria) may result in a better characterization than an evaluation of the "physiological age" arbitrarily established by a non-geriatrician but there is, so far, no trial of NOACs for these patients with the highest rates of adverse events.

\section{FEMALE SEX}

Female sex is an independent risk factor for thrombotic risk in the $\mathrm{CHA}_{2} \mathrm{DS}_{2}$-VASc score, but is not associated with the predicted hemorrhagic risk by the HAS-BLED score. A meta-analysis concluded that there was no increased hemorrhagic risk under anticoagulant treatment for women with AF compared to men 
[20]. Another meta-analysis compared men and women with AF treated with warfarin or NOACs and concluded that the efficacy of NOACs was superior to warfarin for the prevention of thromboembolic events and also reduced the risk of hemorrhagic complications [21]. These results confirm those of post hoc analyses indicating that the efficacy of NOACs in women is similar to that observed in men, with a lower risk of hemorrhagic complications [22-24]. These data therefore argue for a favorable benefit-risk ratio of NOACs in women with AF.

\section{DIABETIC PATIENTS}

Diabetes is an independent risk factor for ischemic stroke. The benefit-risk ratio of NOACs in diabetic patients with AF appears to be favorable, particularly for reducing the risk of thromboembolic events. The meta-analysis by Ruff et al., which included the four available NOACs, showed no significant interaction between diabetes and the benefit-risk ratio of NOACs in patients with AF [17]. However, contradictory data have been reported for hemorrhagic risk in diabetic patients with $\mathrm{AF}$ under NOAC therapy. In the ARISTOTLE study evaluating apixaban versus warfarin, diabetes was associated with a lower decrease of hemorrhagic complications with apixaban than in the general study population [25]. In the ROCKET-AF study comparing rivaroxaban and warfarin, there was no significant interaction between diabetes and the risk of hemorrhagic complications [23]. The RE-LY study comparing dabigatran and warfarin showed comparable bleeding rates in patients with diabetes [26]. The analysis showed a significantly reduced rate of intracranial hemorrhage in diabetic patients receiving dabigatran $110 \mathrm{mg}$ BID compared to warfarin, but a non-significant reduction in diabetic patients receiving dabigatran $150 \mathrm{mg}$ BID [26]. No interaction between diabetic status and the benefits of NOACs was found for the occurrence of ischemic stroke, major bleeding, or intracranial bleeding in the meta-analysis by Patti et al. [27]. The reduction in vascular death rates with NOACs versus warfarin was significant in patients with diabetes and was higher than in non-diabetic patients ( $1.02 \%$ vs $0.27 \%)$, although the interaction was not statistically significant.

\section{EXTREME WEIGHTS}

Obese patients have a higher risk of developing AF than non-obese patients, with a $4 \%$ increase in the risk of $\mathrm{AF}$ per unit increase in body mass index (BMI) [28, 29]. Hypertension, diabetes, and sleep apnea syndrome are often associated with overweight, all further increasing the risk of AF. Weight loss, on the contrary, significantly reduces the severity of AF symptoms [30]. Nutritional management also improves the chance of maintaining sinus rhythm [30]. However, some data suggest a potential obesity paradox in $\mathrm{AF}$, whereby more obese patients may have a lower risk of thromboembolism than non-obese patients despite having a higher risk of AF [31]. There is, to date, no need to consider higher doses of NOACs for AF in obese patients. Similarly, doubling doses of antiplatelet agents for obese patients is not an option after an acute coronary syndrome. However, it has been suggested that NOACs should not be used in patients with a BMI greater than $40 \mathrm{~kg} /$ $\mathrm{m}^{2}$ or a weight greater than $120 \mathrm{~kg}$ because there are limited clinical data available for patients at the extreme of weight, and the available pharmacokinetic and pharmacodynamic evidence suggests that decreased drug exposures, reduced peak concentrations, and shorter half-lives occur with increasing weight, which raises concerns about underdosing in the population with extremely high weights [32]. On the other hand, significant obesity is also linked to poor INR control and lower time in the therapeutic range, and INR testing can be difficult in obese patients as they often have poor venous access.

Low weight, on the other hand, is a bleeding risk factor that must be taken into account. Each NOAC has specificities that need to be known. A risk of NOAC overdosing exists if one does not follow the prescription scheme of the drugs as established for patients with AF in the four major randomized trials. Thus, dosages of apixaban and edoxaban should be adapted 
according to weight [7]. The recommended dose of apixaban is decreased from 5 to $2.5 \mathrm{mg}$ BID in patients with $\mathrm{AF}$ and weight no greater than $60 \mathrm{~kg}$ if they have at least one of the following: age at least 80 years or serum creatinine greater than $133 \mu \mathrm{mol} / \mathrm{L}$. For edoxaban, the recommended dose for AF should be decreased from 60 to $30 \mathrm{mg}$ once daily if the weight is less than $60 \mathrm{~kg}$.

\section{PATIENTS WITH VALVULAR HEART DISEASE}

One should keep in mind that trials comparing VKAs and NOACs in AF were performed in patients with so-called non-valvular $\mathrm{AF}$, although there were slight differences in exclusion criteria related to valve disease in the $\mathrm{AF}$ trials with the four NOACs. The difference between "valvular" and "non-valvular" AF and their respective definitions are still debated [33]. Currently, "valvular" AF would be defined as AF in a patient with mitral stenosis or cardiac mechanical valve prosthesis, and valvular $\mathrm{AF}$ requires treatment with a VKA [7, 33].

Valvular diseases such as mitral regurgitation, aortic stenosis, and aortic regurgitation are not associated with a left atrial low flow and do not seem to intrinsically increase the thromboembolic risk associated with AF. Post hoc analyses suggest that the benefit of NOACs in these pathologies does not differ from that observed for other patients with "non-valvular" AF $[34,35]$. Thus, the classification of "valvular" AF should not be considered to define the etiology of the arrhythmia, but to determine a different risk of thromboembolic events and establish a specific antithrombotic treatment. Patients with "non-valvular" AF may have other types of valvular disease. Thus, it should be emphasized that the definition of "non-valvular" AF does not exclude patients with valvular disease from the possibility of treatment with NOACs $[1,7]$.

Concerning valvular prostheses, the thrombogenic process is likely to be different than in other forms of AF when blood comes into contact with the mechanical valve prosthesis. This may explain the unfavorable results in the only trial conducted to date with NOACs in patients with mechanical prostheses (only a minority of whom had AF) and where warfarin was more effective and safer than dabigatran [36]. On the other hand, AF in patients with a bioprosthesis or valve repair seems to be associated with a thromboembolic risk quite similar to that expected for "non-valvular" AF [37, 38]. A recent analysis of the small subgroup of patients with bioprosthetic valves from the ENGAGE AF-TIMI48 study suggests that edoxaban appears to be a reasonable alternative to warfarin in patients with AF and remote bioprosthetic valve implantation [39]. The expert opinion in the 2015 updated EHRA practical guide on the use of NOACs and recent ESC guidelines thus indicates that patients with bioprostheses seen beyond the third month after surgery are eligible for NOACs.

\section{CONCLUSIONS}

For patients with AF and a significant risk of stroke, oral anticoagulation is highly effective at preventing stroke. Oral direct inhibitors of factors IIa or Xa provide a major improvement for the management of AF patients, since they are easier to use than-and at least as effective aswarfarin for stroke prevention with a more favorable safety profile, especially concerning intracranial bleeding. Safe use of these drugs needs awareness of when to reduce the dose and when the agents should not be used, such as in patients with severe renal impairment and those with mechanical prosthetic valves.

\section{ACKNOWLEDGEMENTS}

This study has received no financial or material support. No funding or sponsorship was received for this study or publication of this article. All named authors meet the International Committee of Medical Journal Editors (ICMJE) criteria for authorship for this manuscript, take responsibility for the integrity of the work as a whole, and have given final approval for the version to be published. Editorial assistance in the preparation of this manuscript was provided by Dr. Jenny Lloyd of MedLink 
Healthcare Communications Limited. Support for this assistance was funded by the authors (Arnaud Bisson, Raphael Philippart).

Disclosures. Laurent Fauchier has served as a consultant for Bayer, BMS/Pfizer, Boehringer Ingelheim, and Daiichi Sankyo and has been on the speakers' bureau of Bayer, BMS/Pfizer, and Boehringher Ingelheim. Denis Angoulvant has received funding for conference travel and educational symposia from Astra Zeneca, EliLilly, Novartis, Bayer, MSD, Amgen, and Pfizer. Nicolas Clementy has been on the speakers' bureau of Medtronic. Dominique Babuty has been on the speakers' bureau of BMS/Pfizer and Medtronic. Arnaud Bisson and Raphael Philippart have nothing to disclose.

Compliance with Ethics Guidelines. This article is based on previously conducted studies and does not involve any new studies of human or animal subjects performed by any of the authors.

Data Availability. Data sharing is not applicable to this article as no datasets were generated or analyzed during the current study.

Open Access. This article is distributed under the terms of the Creative Commons Attribution-NonCommercial 4.0 International License (http://creativecommons.org/licenses/ by-nc/4.0/), which permits any noncommercial use, distribution, and reproduction in any medium, provided you give appropriate credit to the original author(s) and the source, provide a link to the Creative Commons license, and indicate if changes were made.

\section{REFERENCES}

1. Kirchhof P, Benussi S, Kotecha D, et al. 2016 ESC guidelines for the management of atrial fibrillation developed in collaboration with EACTS. Eur Heart J. 2016;37:2893-962.

2. Olesen JB, Lip GYH, Kamper A-L, et al. Stroke and bleeding in atrial fibrillation with chronic kidney disease. N Engl J Med. 2012;367:625-35.
3. Piccini JP, Stevens SR, Chang Y, et al. Renal dysfunction as a predictor of stroke and systemic embolism in patients with nonvalvular atrial fibrillation: validation of the $\mathrm{R}(2) \mathrm{CHADS}(2)$ index in the ROCKET AF (Rivaroxaban Once-daily, oral, direct factor Xa inhibition Compared with vitamin $\mathrm{K}$ antagonism for prevention of stroke and Embolism Trial in Atrial Fibrillation) and ATRIA (anticoagulation and risk factors in atrial fibrillation) study cohorts. Circulation. 2013;127:224-32.

4. Camm AJ, Savelieva I. "R" for "renal" and for "risk": refining risk stratification for stroke in atrial fibrillation. Circulation. 2013;127:169-71.

5. Banerjee A, Fauchier L, Vourc'h P, et al. A prospective study of estimated glomerular filtration rate and outcomes in patients with atrial fibrillation: the Loire Valley atrial fibrillation project. Chest. 2014;145:1370-82.

6. Hohnloser SH, Hijazi Z, Thomas L, et al. Efficacy of apixaban when compared with warfarin in relation to renal function in patients with atrial fibrillation: insights from the ARISTOTLE trial. Eur Heart J. 2012;33:2821-30.

7. Heidbuchel $H$, Verhamme $P$, Alings $M$, et al. Updated European Heart Rhythm Association practical guide on the use of non-vitamin K antagonist anticoagulants in patients with non-valvular atrial fibrillation. Europace. 2015;17:1467-507.

8. Harel Z, Sholzberg M, Shah PS, et al. Comparisons between novel oral anticoagulants and vitamin $\mathrm{K}$ antagonists in patients with CKD. J Am Soc Nephrol. 2014;25:431-42.

9. Del-Carpio Munoz F, Gharacholou SM, et al. Meta-analysis of renal function on the safety and efficacy of novel oral anticoagulants for atrial fibrillation. Am J Cardiol. 2016;117:69-75.

10. Granger CB, Alexander JH, McMurray JJ, et al. Apixaban versus warfarin in patients with atrial fibrillation. N Engl J Med. 2011;365:981-92.

11. Go AS, Hylek EM, Borowsky LH, Phillips KA, Selby JV, Singer DE. Warfarin use among ambulatory patients with nonvalvular atrial fibrillation: the anticoagulation and risk factors in atrial fibrillation (ATRIA) study. Ann Intern Med. 1999;131:927-34.

12. Hanon O, Assayag P, Belmin J, et al. Expert consensus of the French Society of Geriatrics and Gerontology and the French Society of Cardiology on the management of atrial fibrillation in elderly people. Arch Cardiovasc Dis. 2013;106:303-23.

13. Fauchier L, Chaize G, Gaudin A-F, Vainchtock A, Rushton-Smith SK, Cotté F-E. Predictive ability of HAS-BLED, HEMORR2HAGES, and ATRIA bleeding 
risk scores in patients with atrial fibrillation. A French nationwide cross-sectional study. Int J Cardiol. 2016;217:85-91.

14. Mant J, Hobbs FDR, Fletcher K, et al. Warfarin versus aspirin for stroke prevention in an elderly community population with atrial fibrillation (the Birmingham Atrial Fibrillation Treatment of the Aged Study, BAFTA): a randomised controlled trial. Lancet. 2007;370:493-503.

15. Connolly SJ, Eikelboom J, Joyner C, et al. Apixaban in patients with atrial fibrillation. $\mathrm{N}$ Engl J Med. 2011;364:806-17.

16. Budnitz DS, Lovegrove MC, Shehab N, Richards CL. Emergency hospitalizations for adverse drug events in older Americans. N Engl J Med. 2011;365: 2002-12.

17. Ruff CT, Giugliano RP, Braunwald E, et al. Comparison of the efficacy and safety of new oral anticoagulants with warfarin in patients with atrial fibrillation: a meta-analysis of randomised trials. Lancet. 2014;383:955-62.

18. Andreotti F, Rocca B, Husted S, et al. Antithrombotic therapy in the elderly: expert position paper of the European Society of Cardiology Working Group on Thrombosis. Eur Heart J. 2015;36: 3238-49.

19. Fried LP, Tangen CM, Walston J, et al. Frailty in older adults: evidence for a phenotype. J Gerontol A Biol Sci Med Sci. 2001;56:M146-56.

20. Lapner ST, Cohen N, Kearon C. Influence of sex on risk of bleeding in anticoagulated patients: a systematic review and meta-analysis. J Thromb Haemost. 2014;12:595-605.

21. Pancholy SB, Sharma PS, Pancholy DS, Patel TM, Callans DJ, Marchlinski FE. Meta-analysis of gender differences in residual stroke risk and major bleeding in patients with nonvalvular atrial fibrillation treated with oral anticoagulants. Am J Cardiol. 2014;113:485-90.

22. Vinereanu D, Stevens SR, Alexander JH, et al. Clinical outcomes in patients with atrial fibrillation according to sex during anticoagulation with apixaban or warfarin: a secondary analysis of a randomized controlled trial. Eur Heart J. 2015;36:3268-75.

23. Goodman SG, Wojdyla DM, Piccini JP, et al. Factors associated with major bleeding events: insights from the ROCKET AF trial (rivaroxaban once-daily oral direct factor $\mathrm{Xa}$ inhibition compared with vitamin $\mathrm{K}$ antagonism for prevention of stroke and embolism trial in atrial fibrillation). J Am Coll Cardiol. 2014;63:891-900.
24. Ahmad Y, Lip GYH, Apostolakis S. New oral anticoagulants for stroke prevention in atrial fibrillation: impact of gender, heart failure, diabetes mellitus and paroxysmal atrial fibrillation. Expert Rev Cardiovasc Ther. 2012;10:1471-80.

25. Hylek EM, Held C, Alexander JH, et al. Major bleeding in patients with atrial fibrillation receiving apixaban or warfarin: The ARISTOTLE Trial (apixaban for reduction in stroke and other thromboembolic events in atrial fibrillation): predictors, characteristics, and clinical outcomes. J Am Coll Cardiol. 2014;63:2141-7.

26. Brambatti M, Darius H, Oldgren J, et al. Comparison of dabigatran versus warfarin in diabetic patients with atrial fibrillation: results from the RE-LY trial. Int J Cardiol. 2015;196:127-31.

27. Patti G, Di Gioia G, Cavallari I, Nenna A. Safety and efficacy of nonvitamin $\mathrm{K}$ antagonist oral anticoagulants versus warfarin in diabetic patients with atrial fibrillation: a study-level meta-analysis of phase III randomized trials. Diabetes Metab Res Rev. 2016. doi:10.1002/dmrr.2876

28. Wang TJ, Parise H, Levy D, et al. Obesity and the risk of new-onset atrial fibrillation. JAMA. 2004;292:2471-7.

29. Frost L, Hune LJ, Vestergaard P. Overweight and obesity as risk factors for atrial fibrillation or flutter: the Danish diet, cancer, and health study. Am J Med. 2005;118:489-95.

30. Abed HS, Wittert GA, Leong DP, et al. Effect of weight reduction and cardiometabolic risk factor management on symptom burden and severity in patients with atrial fibrillation: a randomized clinical trial. JAMA. 2013;310:2050-60.

31. Proietti M, Guiducci E, Cheli P, Lip GYH. Is there an obesity paradox for outcomes in atrial fibrillation? A systematic review and meta-analysis of non-vitamin $\mathrm{K}$ antagonist oral anticoagulant trials. Stroke. 2017;48:857-66.

32. Martin K, Beyer-Westendorf J, Davidson BL, Huisman MV, Sandset PM, Moll S. Use of the direct oral anticoagulants in obese patients: guidance from the SSC of the ISTH. J Thromb Haemost. 2016;14:1308-13.

33. Fauchier L, Philippart R, Clementy N, et al. How to define valvular atrial fibrillation? Arch Cardiovasc Dis. 2015;108:530-9.

34. Breithardt G, Baumgartner H, Berkowitz SD, et al. Clinical characteristics and outcomes with rivaroxaban vs. warfarin in patients with non-valvular atrial fibrillation but underlying native mitral and aortic valve disease participating in the ROCKET AF trial. Eur Heart J. 2014;35:3377-85. 
35. Siontis KC, Yao X, Gersh BJ, Noseworthy PA. Direct oral anticoagulants in patients with atrial fibrillation and valvular heart disease other than significant mitral stenosis and mechanical valves: a meta-analysis. Circulation. 2017;135:714-6.

36. Van de Werf F, Brueckmann M, Connolly SJ, et al. A comparison of dabigatran etexilate with warfarin in patients with mechanical heart valves: the randomized, phase II study to evaluate the safety and pharmacokinetics of oral dabigatran etexilate in patients after heart valve replacement (RE-ALIGN). Am Heart J. 2012;163(931-7):e1.

37. Philippart R, Brunet-Bernard A, Clementy N, et al. Oral anticoagulation, stroke and thromboembolism in patients with atrial fibrillation and valve bioprosthesis. The Loire Valley atrial fibrillation project. Thromb Haemost. 2016;115:1056-63.

38. Philippart R, Brunet-Bernard A, Clementy N, et al. CHA2DS2-VASc score for predicting stroke and thromboembolism in patients with AF and biological valve prosthesis. J Am Coll Cardiol. 2016;67:343-4.

39. Carnicelli AP, De Caterina R, Halperin JL, et al. Edoxaban for the prevention of thromboembolism in patients with atrial fibrillation and bioprosthetic valves. Circulation. 2017;135:1273-5. 